\title{
Applications of Combination of Computer Simulation and Approximation Modeling in Improving Process Reliability of Vacuum Differential Pressure Casting
}

\author{
Xiaodong Wang ${ }^{1, a^{*},}$ Kai Tang ${ }^{1, b}$, Wenzhi Hu ${ }^{1, c}$, and Qianyi Wang ${ }^{1, d}$ \\ ${ }^{1}$ Systems Engineering Research Institute, Beijing 100036, China \\ axdwxd@163.com, ’wangzi20010@163.com, chappy-fly-man@163.com, dwangqianyi815@sohu.com
}

Keywords: Simulation, approximation modeling, casting process optimization.

\begin{abstract}
Vacuum differential pressure casting is one of the most advanced casting process where there are still serious process defects existed in large complex thin-wall castings. Combination of computer simulation and approximation modeling is applied to improve process reliability of vacuum differential pressure casting in this paper. First, the computer simulation experiments are carried out according to the experiment plan generated by DOE. Then, sample data can be collected from computer simulation by tools in CAD/CAE software or image recognition. Finally, approximation modeling is established and process parameters are optimized, so that process reliability of vacuum differential pressure casting is improved.
\end{abstract}

\section{Introduction}

Vacuum differential pressure casting is one of the most advanced casting process at present. The main technological process of vacuum differential pressure casting is that, initially, make the mold and crucible in the state of negative pressure, and maintain temperature and pressure of the metal fluid in the crucible; then, when filling begins, the pressure on the surface of the molten metal in the crucible increased gradually, and keep pressure negative in the mold, so that there is a pressure difference between the crucible and the mold; subsequently, under the effect of differential pressure, the metal liquid inside the crucible rise steadily at a certain speed and won't stop until the mold is filled completely; finally, when filling ends, pressure in the crucible rises rapidly and differential pressure is maintained for a time to make the metal liquid solidify in the mold.

It have been researched that with a variety of advantages, in the point of view of theory and practice, the casting process of the vacuum differential pressure casting is conducive to improve the quality of castings. Therefore, it becomes one of the most feasible process methods to produce castings with high quality. However, in actual production of large complex thin-wall castings, there are still serious process defects existed in castings, including shrinkage porosity [1].

It is known that the casting process and the solidification process determines the quality of the castings. Applications of more scientific casting process numerical simulation greatly change the traditional foundry industry [2]. The numerical simulation technology in casting process can not only simulate the flow state and solidification method of molten metal in the mode, find form of the flow of molten metal and the pressure change inside the mode, but also simulate the temperature field distribution of molten metal, which can accurately predict the defects in castings. So, the numerical simulation technology can be used to reduce defects, the casting production costs and test cycles, and improve the casting process reliability. By the 1990s, after years of unremitting efforts by researchers, the CAD/CAE technology of foundry technology has developed rapidly. A series of powerful commercial software have emerged at home and abroad, which focused on computerized foundry process solidification simulation analysis, and the two most widely used methods for mathematical simulation of casting are finite element method (FEM) and finite difference method (FDM).

The approximate modeling is a method of approximating a set of input variables and output variables through a mathematical model approach. In the 1970s, L. A. Schmit et al. first introduced 
the concept of approximate modeling in the structural design optimization, accelerated the searching speed of the optimization algorithm, and promoted the application of the optimization algorithm.

\section{Methodology}

The approximation modeling describes the relationship between input variables and output responses by the equation (1).

$$
\mathrm{y}(\mathrm{x})=\tilde{\mathrm{y}}(\mathrm{x})+\varepsilon .
$$

In equation (1), $\mathrm{y}(\mathrm{x})$ indicates actual response value, $\tilde{\mathrm{y}}(\mathrm{x})$ indicates approximate response value, and $\varepsilon$ indicates random error between approximate response value and actual response value, which normally is subjected to $\mathrm{N}\left(0, \sigma^{2}\right)$. The process of creating an approximate model includes collecting sample data, selecting approximate modeling type, initializing the approximate model, verifying the approximate model, optimizing and updating the model, and replacing the simulation program with approximate model finally. The flow chart of approximation modeling is shown in Fig. 1.

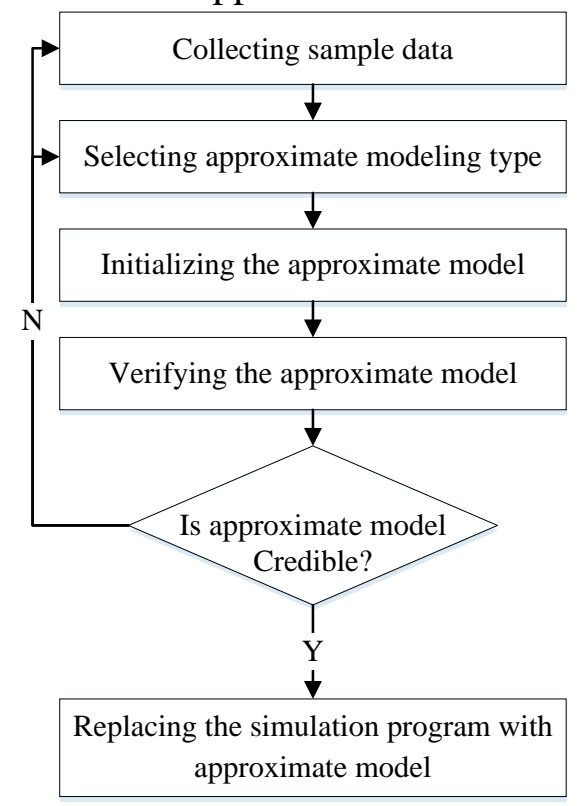

Fig. 1 The flow chart of approximation modeling

In traditional approximation modeling, sample data is collected from DOE (Design of Experiments), randomized trials, physical tests and experience databases [3]. However, due to the high cost of some foundry processes, a large number of actual tests cannot be carried out in production, which means sample data from physical tests cannot be collected. In this paper, computer simulation and approximation modeling are combined together, and sample data will be collected from computer simulation. The flow chart of approximation modeling is shown in Fig. 2.

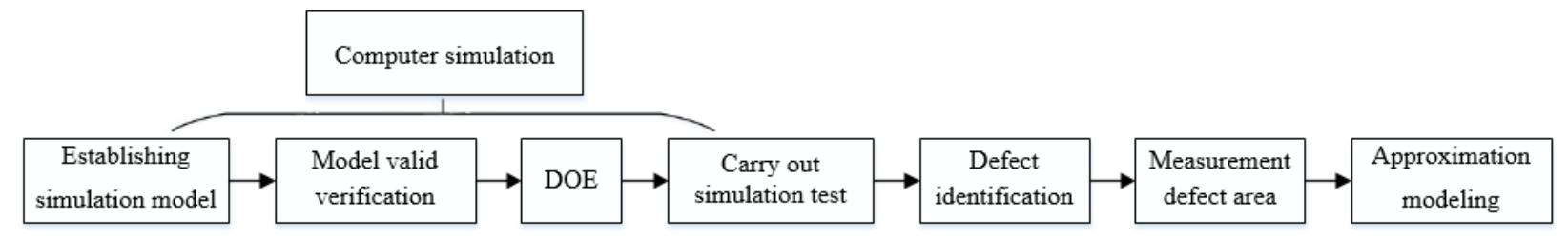

Fig. 2 The flow chart of combination of computer simulation and approximation modeling

It is shown in Fig. 2 that the computer simulation can be divided into four steps. First, establish simulation model in CAD/CAE software for casting, for example, ProCAST, MAGMASOFT, etc. Subsequently, set and adjust the boundary conditions and environmental parameters, carry out preliminary simulation calculation, and make the location and size of the defect in simulation results are roughly the same with the actual production to verify the validity of the model. Then, the 
simulation experiment plan is generated by DOE. Finally, carry out simulation experiments according to the experiment plan. Because simulation tests cannot measure the volume of defects, tools in CAD/CAE software can be used to measure the length of defects, or image recognition can be used to identify defects and measure the defect area, so that the sample data can be collected for approximation modeling.

\section{Case Analysis}

The front casing is the critical component of turboshaft engines, which is produced by vacuum differential pressure casting [4]. Process parameters have a great influence on the quality of castings, and 5 important process parameters and their value range is shown in Table 1, of which acronyms are PT, FT, RT, KP and KT. Combination of computer simulation and approximation modeling in process optimization is used to eliminate process defects and improve process reliability.

Table 1 Five process parameters and their value range

\begin{tabular}{|c|c|c|c|c|c|}
\hline $\begin{array}{c}\text { Process } \\
\text { Parameters }\end{array}$ & $\begin{array}{c}\text { Pouring } \\
\text { Temperature }\left({ }^{\circ} \mathrm{C}\right)\end{array}$ & $\begin{array}{c}\text { Filling } \\
\text { Time }(\mathrm{s})\end{array}$ & $\begin{array}{c}\text { Rising } \\
\text { Pressure } \\
\text { Time }(\mathrm{s})\end{array}$ & $\begin{array}{c}\text { Keeping } \\
\text { Pressure } \\
(\mathrm{kPa})\end{array}$ & $\begin{array}{c}\text { Keeping Pressure } \\
\text { Time }(\mathrm{s})\end{array}$ \\
\hline Value Range & $680 \sim 730$ & $3 \sim 5$ & $2 \sim 4$ & $300 \sim 320$ & $250 \sim 300$ \\
\hline
\end{tabular}

\subsection{Computer Simulation}

ProCAST is used to carry out computer simulation. First, establish simulation model by importing model in Unigraphics NX.

Subsequently, set and adjust the boundary conditions and environmental parameters in ProCAST, and preliminary simulation calculation is carried out. The preliminary simulation calculation result is shown in Fig. 4, which shows that the location and size of the defect in simulation results are roughly the same with the actual production, and the validity of the model is verified.

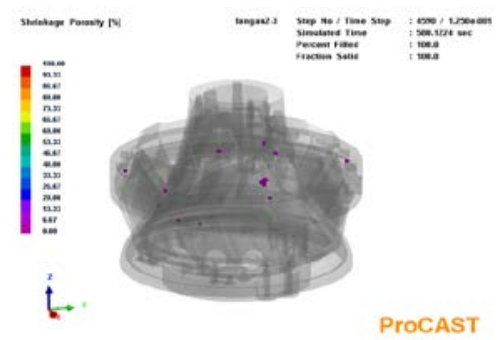

Fig. 4 The preliminary simulation calculation result

Then, Optimal Latin hypercube design, with effective space filling ability, is used to generate simulation experiment plan. According to the experiment plan, 41 simulation experiments are carried out. When simulation experiments finished, image recognition is used to identify defects marked in red and measure the defect area represented by the number of pixels from the $\mathrm{X}, \mathrm{Y}$ and $\mathrm{Z}$ three directions. The image recognition result of No. 1 experiment from the $X$ directions is shown in Fig. 5. The experiment plan and the defect area from the $\mathrm{X}, \mathrm{Y}$ and $\mathrm{Z}$ three directions, which are represented by $\mathrm{X}, \mathrm{Y}$ and $\mathrm{Z}$, is shown in Table 2 .

Table 2 Three Scheme comparing

\begin{tabular}{|c|c|c|c|c|c|c|c|c|}
\hline Number & FT (s) & $\begin{array}{c}\text { KP } \\
(\mathrm{kPa})\end{array}$ & PT $\left({ }^{\circ} \mathrm{C}\right)$ & $\mathrm{RT}(\mathrm{s})$ & $\mathrm{KT}(\mathrm{s})$ & $\mathrm{X}$ & $\mathrm{Y}$ & $\mathrm{Z}$ \\
\hline 1 & 4.80 & 307.5 & 721.25 & 2.70 & 263.75 & 175 & 162 & 156 \\
\hline 2 & 4.50 & 297.5 & 715.00 & 3.45 & 290.00 & 175 & 181 & 174 \\
\hline$\ldots$ & $\ldots$ & $\ldots$ & $\ldots$ & $\ldots$ & $\ldots$ & $\ldots$ & $\ldots$ & $\ldots$ \\
\hline 41 & 3.05 & 302.5 & 706.25 & 2.10 & 277.50 & 64 & 49 & 62 \\
\hline
\end{tabular}




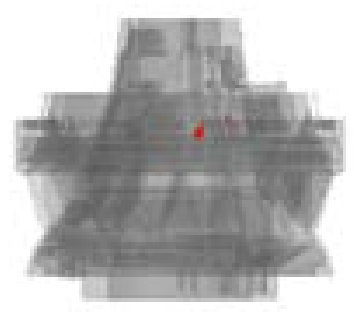

Fig. 5 The image recognition result of No. 1 experiment from the $\mathrm{X}$ directions

\subsection{Approximation Modeling}

Response surface methodology, which can accurately approximate the functional relationship between the factor and the response, is used to establish approximation modeling, where the second-order factors are considered. The insignificant factors are removed according to values of $\mathrm{P}$ in estimate regression coefficient analysis, and the significant factors are used to establish the approximate model, so that values of R-sq and R-sq (adj) reach more than 90\%, and approximate model is optimized. The second order response surface expressions of $\mathrm{X}, \mathrm{Y}$, and $\mathrm{Z}$ is shown by the equation (2), equation (3) and equation (4).

$$
\begin{aligned}
& \mathrm{X}=9536.24+62.26 \times \mathrm{FT}-55.27 \times \mathrm{KP}-7.38 \times \mathrm{PT}-10.23 \times \mathrm{RT}+7.80 \times \mathrm{KT}+0.05 \times \mathrm{KP} * \mathrm{KP} \\
& +0.01 \times \mathrm{KT}^{*} \mathrm{KT}-0.49 \times \mathrm{FT}^{*} \mathrm{KP}+0.02 \times \mathrm{KP} * \mathrm{PT}-0.04 \times \mathrm{KP} * \mathrm{KT}-0.01 \times \mathrm{PT} * \mathrm{KT} . \\
& \mathrm{Y}=8239.39-85.53 \times \mathrm{FT}-18.10 \times \mathrm{KP}-10.51 \times \mathrm{PT}-172.13 \times \mathrm{RT}-8.11 \times \mathrm{KT} \\
& +0.01 \times \mathrm{KT} * \mathrm{KT}+0.23 \times \mathrm{FT} * \mathrm{KT}+0.03 \times \mathrm{KP} * \mathrm{PT}+0.24 \times \mathrm{PT} * \mathrm{RT} \\
& \mathrm{Z}=1365.77-162.43 \times \mathrm{FT}-1.53 \times \mathrm{PT}-193.52 \times \mathrm{RT}+5.49 \times \mathrm{KT}+0.21 \times \mathrm{FT} * \mathrm{PT} \\
& +0.26 \times \mathrm{PT} * \mathrm{RT}-0.01 \times \mathrm{PT} * \mathrm{KT} .
\end{aligned}
$$

5 important process parameters are optimized by response optimizer and optimization values are shown in Table 3. Pass rate increased by $20 \%$ after optimization results are applied to the production.

Table 3 Optimization values of important process parameters

\begin{tabular}{|c|c|c|c|c|c|}
\hline $\begin{array}{c}\text { Process } \\
\text { Parameters }\end{array}$ & $\begin{array}{c}\text { Pouring } \\
\text { Temperature }\left({ }^{\circ} \mathrm{C}\right)\end{array}$ & $\begin{array}{c}\text { Filling } \\
\text { Time } \\
(\mathrm{s})\end{array}$ & $\begin{array}{c}\text { Rising } \\
\text { Pressure } \\
\text { Time }(\mathrm{s})\end{array}$ & $\begin{array}{c}\text { Keeping } \\
\text { Pressure } \\
(\mathrm{kPa})\end{array}$ & $\begin{array}{c}\text { Keeping } \\
\text { Pressure Time } \\
(\mathrm{s})\end{array}$ \\
\hline $\begin{array}{c}\text { Optimization } \\
\text { Value }\end{array}$ & 730 & 5 & 2 & 310.3 & 280.34 \\
\hline
\end{tabular}

\section{Summary}

Combination of computer simulation and approximation modeling is applied to improve process reliability of vacuum differential pressure casting in this paper. First, the computer simulation experiments are carried out according to the experiment plan generated by DOE. Then, sample data is collected from computer simulation by tools in CAD/CAE software or image recognition. Finally, approximation modeling is established and process parameters are optimized. Pass rate can increased greatly after optimization results are applied to the production and process reliability of vacuum differential pressure casting is improved.

\section{References}

[1] Xin-lei L, Qi-tang H, Wan-qi J, Yu-chuan Z, Development of pressure control system in counter gravity casting for large thin-walled A357 aluminum alloy components, Transactions of Nonferrous 
Metals Society of China. (2008) 847-851.

[2] A. Dabade U, C. Bhedasgaonkar R, Casting Defect Analysis using Design of Experiments (DoE) and Computer Aided Casting Simulation Technique, Procedia CIRP. (2013) 616-621.

[3] Yoon A, P. Khargonekar and K. Hebbale, Design of computer experiments for open-loop control and robustness analysis of clutch-to-clutch shifts in automatic transmissions in American Control Conference. (1997).

[4] Zhaojun Hao, Min Huang, The process reliability analysis of the front casing of the turbo shaft engine, Aussino Academic Publishing House. (2016) 324-328. 